09

\title{
Исследование спектральных свойств калиево-алюмоборатных стекол, легированных хромом
}

\author{
() Д.А. Агафронова, А.Н. Бабкина , К.С. Зырянова, А.И. Игнатьев, \\ Н.В. Никоноров, К.В. Орешкина \\ Университет ИТМО, \\ Санкт-Петербург, Россия \\ ฯ E-mail: babkina.anastasya@bk.ru
}

\begin{abstract}
Исследованы спектральные свойства калиево-алюмоборатных стекол, активированных разной концентрацией соединений трехвалентного хрома. Определены температуры стеклования состава $\left(434^{\circ} \mathrm{C}\right)$ и объемной кристаллизации матрицы стекла $\left(600^{\circ} \mathrm{C}\right)$. Термообработка стекла при температуре кристаллизации приводит к появлению интенсивных узких полос люминесценции в области $685-715 \mathrm{~nm}$, что связано с выделением в матрице стекла кристаллической фазы $\mathrm{LiAl}_{7} \mathrm{~B}_{4} \mathrm{O}_{17}: \mathrm{Cr}^{3+}$, в которой хром занимает позиции в высокосимметричном октаэдрическом окружении. Концентрационные зависимости времени жизни и квантового выхода показали наличие концентрационного тушения люминесценции при увеличении содержания хрома в стекле от 0.05 до $0.2 \mathrm{~mol} \%$. Максимальное значение квантового выхода составило $30 \%$.
\end{abstract}

Исследование выполнено при финансовой поддержке РФФИ в рамках научного проекта № 18-33-00780.

DOI: 10.21883/FTT.2019.05.47594.31F

\section{1. Введение}

На данный момент наиболее распространенные источники энергии в мире основаны главным образом на легкодоступном ископаемом органическом топливе (нефть и газ), запасы которого быстро уменьшаются. Нет никаких сомнений в том, что экологически чистая и безопасная солнечная энергия является одним из решений энергетической проблемы. При этом актуальной задачей становится разработка надлежащих методов накопления, хранения и преобразования солнечного света. Первой реализацией этих методов было преобразование солнечной энергии в тепловую [1]. Затем было освоено преобразование солнечной энергии в электрический ток $[2,3]$ или энергию химических реакций [4]. Концентрация солнечного света на устройствах фотовольтаики (например, на основе GaAs) изначально производилась с помощью параболических зеркал или линз Френеля. Конструкция и принцип работы плоских солнечных концентраторов на базе люминесцентных материалов впервые были предложены в работе [5]. В работах [6-8] в качестве люминесцентного вещества были использованы органические красители, которые обладали хорошими характеристиками в плане преобразования солнечной энергии, но не были стабильны в долгосрочной перспективе. В связи с этим, начиная с 1970-х годов, стали активно развиваться люминесцентные солнечные концентраторы (ЛСК) на основе неорганических стекол с люминесцентными допантами: ионами редкоземельных элементов (РЗИ) [9-12] и ионами переходных металлов (в основном, хрома и марганца) [11,13-16].

Люминесценция ионов переходных металлов обусловлена внутрифигурационными $d-d$-переходами и приходится на видимую область спектра, что делает такие материалы перспективными для использования в ЛСК. Преимущество переходных металлов перед РЗИ заключается в том, что силы осцилляторов первых выше, а полосы поглощения и люминесценции имеют большую спектральную ширину. Последнее связано с более сильным взаимодействием иона с окружающим полем лигандов [17], что приводит к расщеплению уровней, с которых осуществляются излучательные переходы.

Известно, что ионы трехвалентного хрома в стеклах обладают двумя широкими полосами поглощения, связанными со спин-разрешенными переходами ${ }^{4} A_{2}-{ }^{4} T_{1}$ (порядка $23000 \mathrm{~cm}^{-1}$ ) и ${ }^{4} A_{2}-{ }^{4} T_{2}$ (около $16000 \mathrm{~cm}^{-1}$ ). В щелочносиликатных стеклах коэффициент молярной экстракции второй полосы составляет около $20 \mathrm{~mol}^{-1} \mathrm{~cm}^{-1}$ [18]. Эти полосы относятся к ионам $\mathrm{Cr}^{3+}$, находящимся в низкосимметричном поле лигандов, для которого уровень ${ }^{4} T_{2}$ лежит ниже первого дублета ${ }^{2} E$. Во всех позициях с низкосимметричным окружением люминесценция ионов $\mathrm{Cr}^{3+}$ при комнатной температуре состоит из широкой бесструктурной полосы в ближней инфракрасной области вследствие колебательноуширенного перехода ${ }^{4} T_{2}-{ }^{4} A_{2}$. В зависимости от состава стекла максимум такого спектра варьируется в диапазоне $750-850 \mathrm{~nm}[19,20]$ при возбуждении излучением с длиной волны $453 \mathrm{~nm}$. При этом максимальный квантовый выход люминесценции ионов хрома был получен для щелочносиликатных стекол и составил 17.5\% [19].

Внедрение ионов хрома в высокосимметричное окружение приводит к появлению интенсивных полос люминесценции, связанных с переходами ${ }^{2} E-{ }^{4} A_{2}$, которые можно наблюдать в кристаллах рубина [21] и александрита [22]. Таким образом, улучшения люминесцентных характеристик ионов хрома можно добиться путем введения ионов в матрицу стеклокристаллических материалов (стеклокерамик), которые объединяют достоинства 
стекол и кристаллов. Стеклокерамика, в которой $\mathrm{Cr}$ (III) будет сконцентрирован в кристаллитах, распределенных в аморфной матрице и имеющих размеры, меньшие длины волны видимого излучения, будет прозрачной в видимой области спектра и при этом обладать высокой квантовой эффективностью.

В работе [23] показаны основные принципы синтеза стеклокерамик на основе боратного стекла, активированного ионами хрома. Полученные стекла были прозрачны в видимом диапазоне, имели квантовый выход люминесценции порядка $30-50 \%$ и были признаны перспективными для использования в волоконных усилителях в системах передачи информации, в лазерных биомедицинских системах и в люминесцентных солнечных концентраторах. Таким образом, настоящая работа посвящена исследованию спектральных свойств вышеупомянутых стекол и является логическим продолжением работы [23].

Целью настоящей работы является исследование спектральных свойств калиево-алюмоборатных стекол, активированных ионами трехвалентного хрома, в зависимости от его концентрации в матрице стекла.

\section{2. Методика исследования}

Были синтезированы стекла состава $12.5 \mathrm{~K}_{2} \mathrm{O}-$ $12.5 \mathrm{Li}_{2} \mathrm{O}-25 \mathrm{Al}_{2} \mathrm{O}_{3}-50 \mathrm{~B}_{2} \mathrm{O}_{3}$ (mol\%), содержащие разную концентрацию ионов хрома. Хром был введен в состав стекла в виде оксида $\mathrm{Cr}_{2} \mathrm{O}_{3}$. Для улучшения условий образования нанокристаллов при использовании малых концентраций хрома в стекла вводились соединения сурьмы $\left(1 \mathrm{~mol} \% \mathrm{Sb}_{2} \mathrm{O}_{3}\right)$ и фтора $\left(2.2 \mathrm{~mol} \%\left(\mathrm{NH}_{4}\right) \mathrm{HF}_{2}\right)$. Синтез исходного стекла проходил при температуре $1400^{\circ} \mathrm{C}$ в корундовых тиглях с перемешиванием расплава платиновородиевой мешалкой. Отжиг стекла производился при температуре порядка $350-400^{\circ} \mathrm{C}$. Для выявления оптимальных режимов термообработок все стекла были исследованы методом дифференциальной сканирующей калориметрии с использованием калориметра STA 449F1 Jupiter (Netzsch). Спектры поглощения регистрировались на спектрофотометре Lambda 650 в

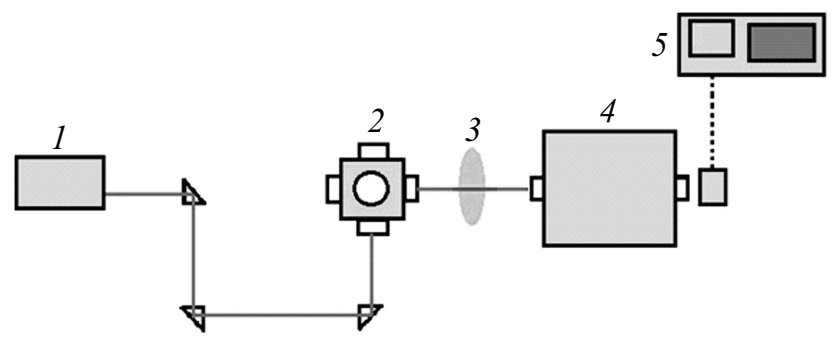

Pис. 1. Схема установки для регистрации кривых затухания люминесценции. На схеме: 1 - импульсный лазер, 2 криостат, 3 - короткофокусный объектив, 4 - монохроматор, 5 - осциллограф.

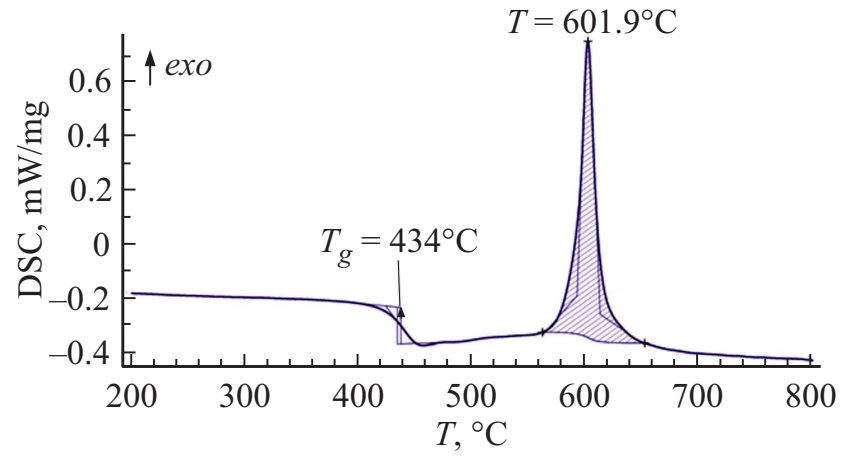

Рис. 2. Термограмма ДСК боратного стекла.

диапазоне $300-850 \mathrm{~nm}, \mathrm{c}$ шагом $0.1 \mathrm{~nm}$ и временем интеграции $1 \mathrm{sec}$. Абсолютный квантовый выход и спектр люминесценции были измерены на установке Absolute PL Quantum Yield Measurement System (фирма Hamamatsu), включающей в себя ксеноновую лампу, монохроматор, интегрирующую сферу и спектрометр. Кривые затухания в максимуме полосы люминесценции были измерены на установке, схема которой представлена на рис. 1. Излучение импульсного лазера с длиной волны $532 \mathrm{~nm}$ возбуждает люминесценцию в образце, сигнал от которого регистрируется приемником, и на осциллографе наблюдается кривая затухания люминесценции.

\section{3. Результаты исследования}

В ходе исследования исходных стекол методом дифференциальной сканирующей калориметрии, была определена температура стеклования, которая составила $434^{\circ} \mathrm{C}$, и температура максимума области кристаллизации, приходящаяся на $600^{\circ} \mathrm{C}$ (рис. 2). Изотермическая обработка исходных образцов стекла проводилась при температуре кристаллизации наноразмерной фазы в течение $2 \mathrm{~h}$. В результате термообработки в матрице стекол выделилась кристаллическая фаза $\mathrm{LiAl}_{7} \mathrm{~B}_{4} \mathrm{O}_{17}: \mathrm{Cr}^{3+}$ [23]. Средний размер кристаллических частиц составил порядка $20 \mathrm{~nm}$.

На рис. 3, $a$ представлены спектры поглощения боратных стекол после термообработки при $T=600^{\circ} \mathrm{C}$ в течении двух часов с разными концентрациями хрома. Спектры поглощения стекол, полученных после синтеза, содержат две широкие полосы поглощения, одна из которых расположена в области $610 \mathrm{~nm}$, а вторая в области $420 \mathrm{~nm}$. Длинноволновая полоса имеет типичные признаки полосы поглощения ионов $\mathrm{Cr}^{3+}$, которая соответствует переходу ${ }^{4} A_{2}-{ }^{4} F_{2}$, а коротковолновая полоса соответствует высокоэнергетическому переходу ${ }^{4} A_{2}-{ }^{4} F_{1}[24,25]$. Из рис. $3, a$ видно, что после проведения термообработки при температуре $600^{\circ} \mathrm{C}$ произошел коротковолновый сдвиг максимумов полос поглощения. С увеличением концентрации хрома в стекле, интенсивность полос увеличилась. 

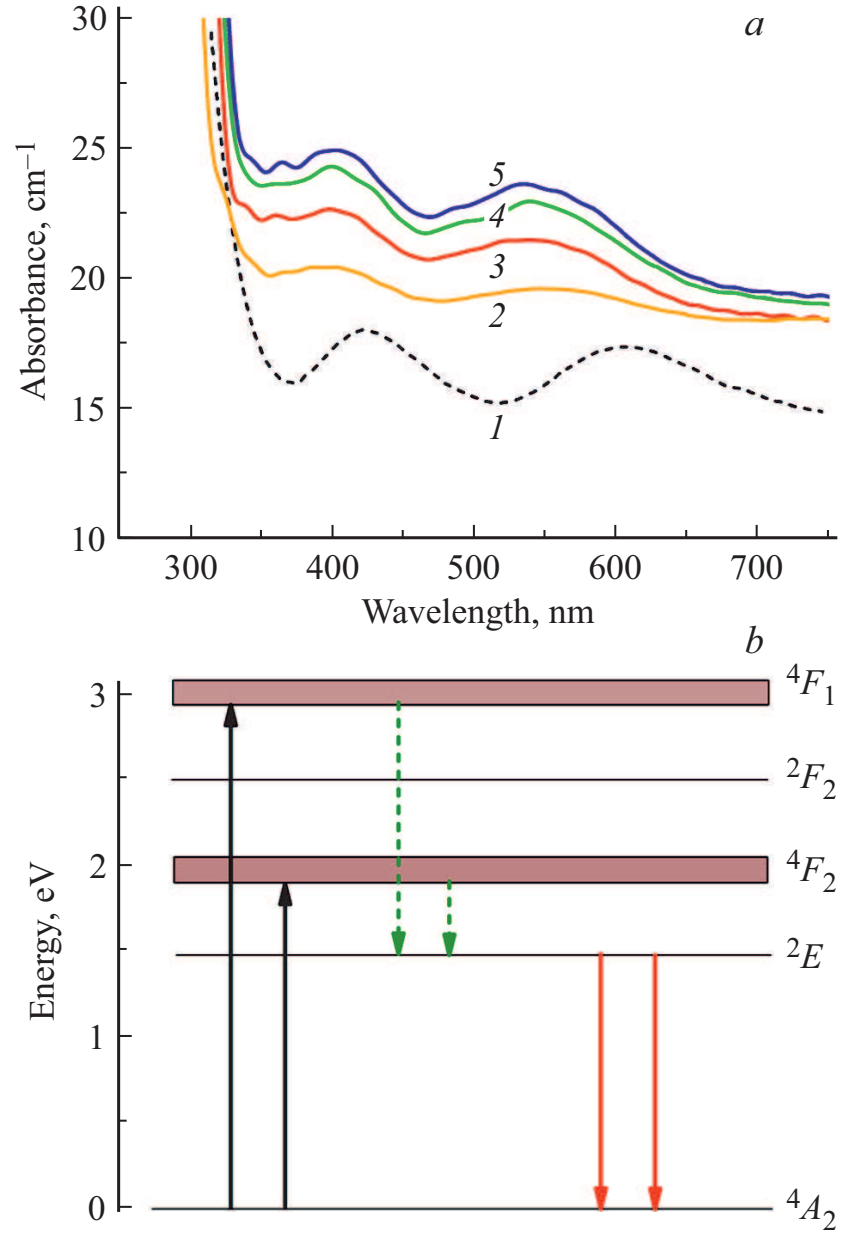

Рис. 3. $a-$ спектры поглощения боратных стекол: $1-$ до термообработки и после термообработки при $T=600^{\circ} \mathrm{C}(2 \mathrm{~h})$ с разными концентрациями хрома: $2-0.01,3-0.025$, $4-0.05,5-0.1 \mathrm{~mol} \%$; $b-$ схема энергетических уровней ионов хрома в высокосимметричном окружении.

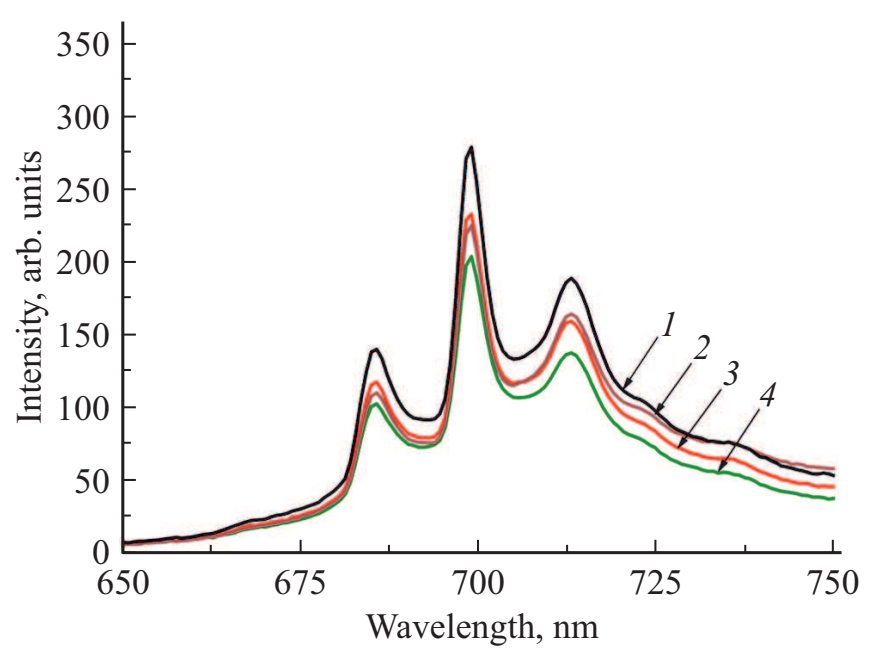

Рис. 4. Спектры люминесценции боратных стекол после термообработки при $T=600^{\circ} \mathrm{C}(2 \mathrm{~h}) \mathrm{c}$ разными концентрациями хрома: $1-0.1 ; 2-0.05 ; 3-0.025$ и $4-0.01 \mathrm{~mol} \%$.
Концентрационная зависимость квантового выхода люминесценции хромсодержащих боратных стекол

\begin{tabular}{c|c}
\hline $\begin{array}{c}\text { Концентрация } \\
\mathrm{Cr}_{2} \mathrm{O}_{3}, \mathrm{~mol} \%\end{array}$ & $\begin{array}{c}\text { Квантовый } \\
\text { выход, \% }\end{array}$ \\
\hline 0.01 & 28.6 \\
0.05 & 29.1 \\
0.1 & 30.1 \\
0.2 & 23.1
\end{tabular}

На рис. 4 представлены спектры люминесценции боратных стекол с разной концентрацией хрома после термообработки при температуре $600^{\circ} \mathrm{C}$. Отчетливо видно, что интенсивность люминесценции в области $700 \mathrm{~nm}$ возрастает с увеличением концентрации хрома. Именно в этой области спектра расположены $R$-линии объемных кристаллов, активированных трехвалентным хромом, соответствующие переходам ${ }^{2} E-{ }^{4} A_{2}[26,27]$.

В ходе исследований была получена зависимость времени жизни люминесценции от концентрации ионов хрома, вводимых в стекло в процессе синтеза. Из рис. 5 следует, что при увеличении содержания хрома в стекле от 0.025 до $0.1 \mathrm{~mol} \%$ происходит уменьшение времени жизни на длинах волн максимумов полос люминесценции. Как можно заметить из таблицы, значения квантового выхода, начиная с $0.05 \mathrm{~mol} \%$ хрома в стекле, уменьшаются при увеличении концентрации люминесцентных центров.

Уменьшение квантового выхода и значений времени жизни вызвано концентрационным тушением люминесценции. Это объясняется тем, что при увеличении концентрации центры возбуждения начинают мигрировать по ансамблю центров. В результате, миграция приводит к увеличению вероятности безызлучательных переходов.

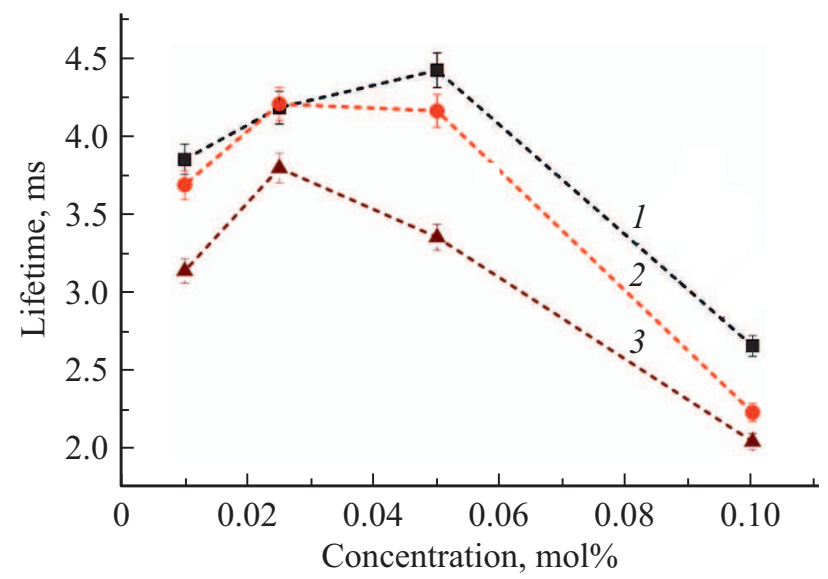

Рис. 5. Концентрационная зависимость времени жизни люминесценции боратных стекол после термообработки при $T=600^{\circ} \mathrm{C}(2 \mathrm{~h})$ на соответствующих длинах волн: $1-685 \mathrm{~nm}$; $2-700 \mathrm{~nm} ; 3-715 \mathrm{~nm}$ (линии, соединяющие экспериментальные точки, представлены для лучшей визуализации результатов). 


\section{4. Заключение}

В результате работы были синтезированы стекла, содержащие разную концентрацию ионов хрома, которые были термообработаны при температуре максимума области кристаллизации на кривой ДСК. Измерены спектры поглощения исходных стекол и спектры люминесценции термообработанных стекол, которые оказались схожими с люминесценцией хромсодержащих кристаллов в области R-линий, в связи с выделением после термообработки в матрице стекла кристаллической фазы $\mathrm{LiAl}_{7} \mathrm{~B}_{4} \mathrm{O}_{17}: \mathrm{Cr}^{3+}$. Максимально значение квантового выхода, соответствующее концентрации хрома в стекле $0.05 \mathrm{~mol} \%$, составляет $30 \%$ для термообработки при $600^{\circ} \mathrm{C}$ длительностью два часа. Были измерены кривые затухания люминесценции хромсодержащих стекол и получена зависимость времени жизни от концентрации ионов хрома в стекле. Концентрационные зависимости времени жизни и квантового выхода показали наличие концентрационного тушения люминесценции при увеличении содержания хрома в стекле от 0.01 до $0.2 \mathrm{~mol} \%$.

\section{Список литературы}

[1] A.B. Meinel. Solar Energy Mater. Solar Cells 32, 327 (1994).

[2] M.A. Baldo. Opt. Eng. 20, 887 (1981).

[3] R.L. Hammond, C.E. Backus. Renew. Energy 5, 268 (1994).

[4] R. Reisfeld, C.K. Jorgensen. Struct. Bond. 49, 1 (1982).

[5] W.H. Weber, J. Lambe. Appl. Opt. 15, 2299 (1976).

[6] J.S. Batchelder, A.H. Zewai, T. Cole. Appl. Opt. 18, 3090 (1979).

[7] J.S. Batchelder, A.H. Zewail, T. Cole. Appl. Opt. 20, 3733 (1981).

[8] L.R. Wilson, B.S. Richards. Appl. Opt. 48, 212 (2009).

[9] R. Reisfeld, Y. Kalisky. Chem. Phys. Lett. 80, 178 (1981).

[10] R. Reisfeld, L. Boehm. J. Non. Cryst. Solids. 16, 83 (1974).

[11] A. van Die, A.J. Faber, G. Blasse, W.F. Van Der Weg. J. Phys. Chem. Solids. 47, 1081 (1986).

[12] G. Folcher, N. Keller, J. Paris. Solar. Energy Mater. 10, 303 (1984).

[13] R. Reisfeld, A. Kisilev, E. Greenberg. Chem. Phys. Lett. 104, 2 (1984).

[14] N. Saad, M. Haouari, A. Bulou, A. Hadi Kassiba, H. Ben Ouada. Mater. Chem. Phys. 212, 461 (2018).

[15] A. van Die, G. Blasse, W.F. Van Der Weg. Mater. Chem. Phys. 14, 513 (1986).

[16] N. Neuroth, R. Haspel. Solar. Energy Mater. 16, 235 (1987).

[17] C.J. Ballhausen. Q. Rev. Chem. Soc. 5, 373 (1971).

[18] A. Kisilev, R. Reisfeld. Sol. Energy 33, 163 (1984).

[19] L.J. Andrews, A. Lempicki, B.C. McCollum. J. Chem. Phys. 74, 5526 (1981).

[20] A. Kisilev, R. Reisfeld, E. Greenber, A. Buch, M. Ish-Shalom. Chem. Phys. Lett. 105, 405 (1984).

[21] D.F. Nelson, M.D. Sturge. Phys. Rev. 137, 4 A (1965).

[22] R.C. Powell, L. Xi, X. Gang. Phys. Rev. A 32, 2788 (1985).

[23] А.Н. Бабкина, А.Д. Горбачев, К.С. Зырянова, Н.В. Никонов, Р.К. Нурыев, С.А. Степанов. Оптика и спектроскопия 123, 337 (2017).
[24] C. Koepke, K. Wisniewski, M. Grinberg, G.H. Beall. Spectrochim. Acta Part A Mol. Biomol. Spectrosc. 54, 1725 (1998).

[25] C. Koepke, K. Wisniewski, M. Grinberg, F. Rozploch. Analysis 14, 11553 (2002).

[26] А.Б. Кулинкин, С.П. Феофилов, Р.И. Захарченя. ФТТ 42 , 835 (2000).

[27] А.А. Каплянский, А.Б. Кулинкин, С.П. Феофилов, Р.И. Захарченя, Т.Н. Василевская. ФТТ 40, 1442 (1998).

Редактор К.В. Емцев 